\title{
TRAKTORANVÄNDNINGENS UTVECKLING PÅ ETT ANTAL BOKFORINGSGARDAR
}

\author{
N. Westermarck \& K. J. Weckman \\ Helsingfors universitets lantbruksekonomiska institution
}

Mottaget 16. 2. 1961

Den starka mekanisering, som ägt rum inom jordbruket under 1950-talet, framgår tydligt bl.a. därav, att medan antalet jordbrukstraktorer vid lantbruksräkningen år 1950 uppgick till 14450 hade antalet år 1959 stigit till inte färre än 74600 .

Då man beaktar den stora roll traktorn spelar i det moderna jordbruket, är det av ett visst intresse att vinna kännedom om huru effektivt traktorerna utnyttjas. En viss uppfattning härom lämnar uppgifterna om traktorernas användningstid på bokföringsgårdarna. Tyvärr finnes inga uppgifter före år 1952/53.

\begin{tabular}{|c|c|c|}
\hline Bokföringsår & $\begin{array}{l}\text { Traktortimmar } \\
\text { per gård }\end{array}$ & $\begin{array}{l}\text { i medeltal } \\
\text { per traktor }\end{array}$ \\
\hline $1952 / 53 \ldots \ldots \ldots \ldots \ldots$ & 157 & 449 \\
\hline $1953 / 54 \ldots \ldots \ldots \ldots \ldots \ldots$ & 210 & 494 \\
\hline $1954 / 55 \ldots \ldots \ldots \ldots \ldots \ldots$ & 219 & 467 \\
\hline $1955 / 56 \ldots \ldots \ldots \ldots \ldots \ldots$ & 250 & 473 \\
\hline $1956 / 57 \ldots \ldots \ldots \ldots \ldots \ldots$ & 273 & 479 \\
\hline $1957 / 58 \ldots \ldots \ldots \ldots \ldots \ldots$ & 298 & 469 \\
\hline $1958 / 59 \ldots \ldots \ldots \ldots \ldots$ & 321 & 490 \\
\hline
\end{tabular}

Under sju år har sålunda antalet traktortimmar per bokföringsgård ökat till det dubbla. Användningstiden per traktor visar däremot ingen bestämd utvecklingstendens.

Närmare besked om användningstidens fördelning på olika arbetsoperationer lämnar uppgifterna från bokföringsgårdarna icke. 


\section{Undersökningens syfte och uppläggning}

Vid Helsingfors universitets lantbruksekonomiska institution utfördes åren 1950, 1951 och 1952 en undersökning rörande bl.a. traktorernas användning på bokföringsgårdarna. Resultaten har återgetts av WESTERMARCK ${ }^{1}$ och KARELL ${ }^{2}$. Syftet med föreliggande undersökning är att utröna, i vilken mån förändringar sedan dess ägt rum i fråga om traktorernas användning och användningstidens fördelning på olika arbetsoperationer.

Undersökningen har i likhet med vad som var fallet med den tidigare undersökningen utförts på lantbruksstyrelsens bokföringsgårdar. Antalet bokföringsgårdar med egen traktor uppgick år 1952 till 327 av sammanlagt 935 bokföringsgårdar, men hade år 1958 ökat till 707 av sammanlagt 1216 bokföringsgårdar. En avsevärd förändring inom traktoriseringen har sålunda ägt rum. Då man dessutom beaktar, att bokföringsgårdarna undergår förskjutningar från år till år och att endast en del av de gårdar, som äger traktor, fört de för undersökningen nödvändiga anteckningarna, är det förståeligt, att det tyvärr endast i tämligen ringa utsträckning varit samma gårdar, som deltagit $\mathrm{i}$ de båda undersökningarna.

I föreliggande undersökning har bokföringsgårdarna indelats i de traditionella storleksgrupperna: Grupp I under 10.1 ha jordbruksjord, grupp II $10.1-25$ ha, grupp III $25.1-50$ ha och grupp IV över 50 ha. I den regionala indelningen har likaså den traditionella indelningen följts. Undersökningsområdena är som bekant fem, nämligen: Södra Finland (S-F), Mellersta Finland (M-F), Södra Österbotten $(\mathrm{S}-\mathrm{O})$, Norra Österbotten $(\mathrm{N}-\mathrm{O})$ och Nordöstra Finland $(\mathrm{N}-\mathrm{F})$.

Undersökningen omfattade ett år dvs. kalenderåret 1958. Antalet gårdar, som fullföljde undersökningen genom att dagligen anteckna den tid, som gårdens traktor(er) använts för olika arbetsoperationer, var 279. Emellertid måste första storleksgruppens gårdar (10.1 ha) helt lämnas bort, enär inga traktorer i denna grupp förekom under den tidigare undersökningen $1950-52$, varför någon jämförelse ej var möjlig att utföra.

På grund av den svaga representativiteten i nu föreliggande undersökning sammanslogs södra och norra Österbotten till ett område. Det oaktat var antalet österbottniska gårdar med traktor $\mathrm{i}$ fjärde storleksgruppen så ringa, att den lämnats utanför. Av samma orsak lämnades samtliga gårdar inom Nordöstra Finlands undersökningsområde bort. Det slutliga antalet gårdar var sålunda 240 år 1958 mot 65 åren $1950-52$.

Antalet hästkrafter per traktor var i medeltal 30.8 och medelåldern 4.5 år medan 15 olika traktormärken var representerade. Arbetsoperationerna uppdelades på följande grupper:

1. Jordbearbetning omfattande plöjning och harvning.

2. Sddd och gödselspridning omfattande sådd, vältning och spridning av stallgödsel, handelsgơdsel och kalk.

1 Westermarck, N. 1955. The use of certain machines on Finnish farms. Acta Agric. Scand. 5, 2-3, 295-311. Uppsala.

' KARELL, RALF, 1956. Traktoranvändningen på vissa bokföringsgårdar under åren $1950-52$. (Maskinskriven laudaturavhandling). 
3. Skötsel av grödan omfattande bekämpning av ogräs och skadedjur, gallring, potatiskupning etc.

4. Skörd av grödan omfattande slåtter, huggning av säd, upptagning av rotfrukter och potatis.

5. Tröskning omfattande traktorns användning vid bogsering av skördetröska ävensom vid stationär tröskning.

6. Jordbrukets transporter.

7. Skogsbrukets transporter.

8. Markanläggningar omfattande dikesplogning, täckdikning etc.

9. Stationär drift omfattande vedkapning, klabbning, sảgning, pärthyvling, framställning av hackelse, malning, cementtillverkning, tegelslagning etc. Stationär användning vid tröskning ingår $\mathrm{i}$ gruppen tröskning.

10. Övriga arbeten omfattande arbetsoperationer av blandad art sảsom snöplogning, vägunderhåll, privata resor etc.

11. Biförtjänster omfattande arbeten utförda ât andra.

Timåtgången återges såväl per gård som per traktor. I förra fallet ingår i tidsåtgången såväl egna som främmande traktorers användningstid, i senare fallet endast egna traktorers.

\section{Undersökningens resultat}

Det faktum, att antalet gårdar, som deltagit såväl i undersökningen för åren 1950 - 52 som i föreliggande undersökning, är tämligen ringa dvs. endast 24 är givetvis en svaghet, då det gäller att jämföra de bägge undersökningarnas resultat med varandra. $\AA$ andra sidan återspeglar den starka ökningen av traktoriserade bokföringsgårdar den utveckling, som faktiskt ägt rum inom jordbruket på 1950talet.

Den mellan perioderna 1950 - 52 och 1958 inträffade utvecklingen ifråga om traktorernas användning återges i grova drag inom ramen för gruppmedeltal från samtliga gårdar, som innehaft traktor under något av åren $1950-52$ respektive år 1958. I syfte att erhålla en mera preciserad bild jämföres med varandra resultaten från de gårdar, vilka deltagit såväl i undersökningen 1950--52, som i nu föreliggande undersökning för år 1958.

Tabell 1 lämnar upplysningar om traktorernas användning per gård under de bägge undersökningsperioderna.

Tabellen utvisar att tidsåtgången ökat i samtliga grupper, om man undantager grupp M-F II, för vilken emellertid representativiteten är svagast. Mest påtaglig har användningstidens ökning varit inom grupperna S-F III och S-F IV. Då man arbetsgruppvis granskar användningstidens förändringar, finner man, att följande arbetsgrupper utvisar en tydlig ökning; sådd och gödselspridning, skörd av grödan, skogsbrukets transporter, markanläggningar och övriga arbeten. En ökning ehuru ej lika genomgående annoteras för jordbrukets transporter. Däremot företer grupperna jordbearbetning och stationär drift icke någon ökning. Utvecklingen för biförtjänstarbeten tyder närmast på en avtagande tendens. För skötsel av grödan har under bägge perioderna endast en obetydlig tid offrats. Av intresse är även att konstatera huru medelarealen för gårdar med traktor förskjutits nedåt. 


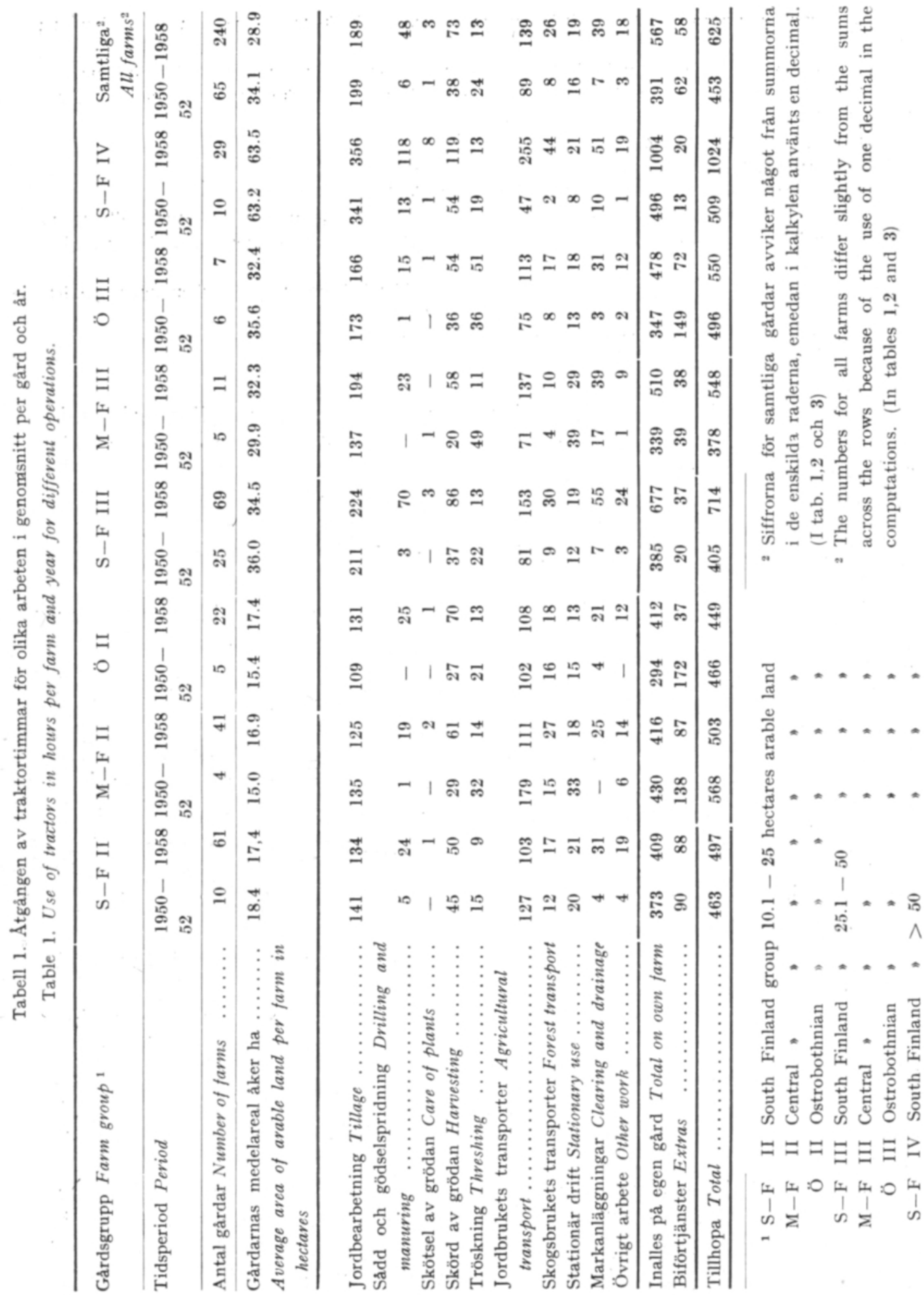




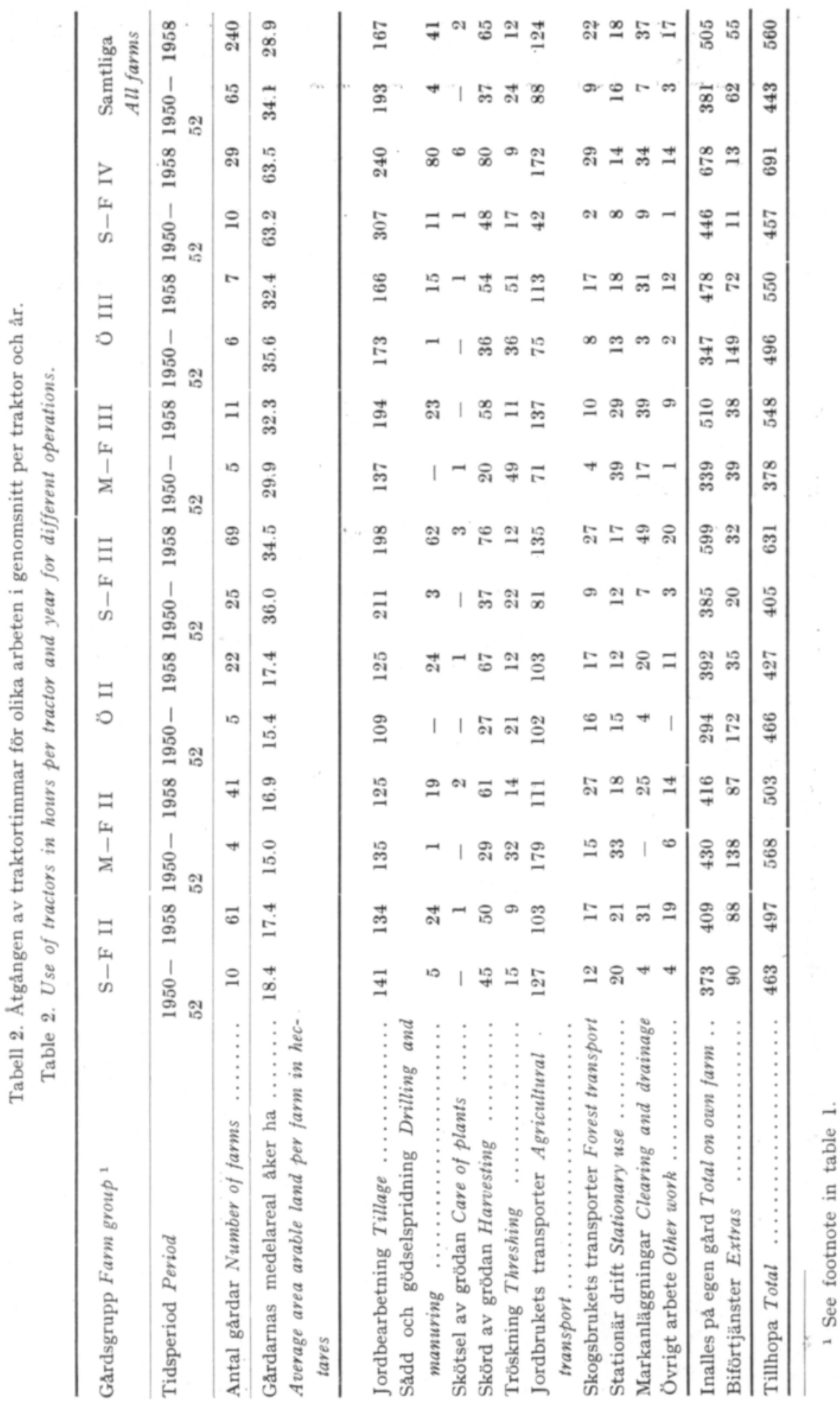




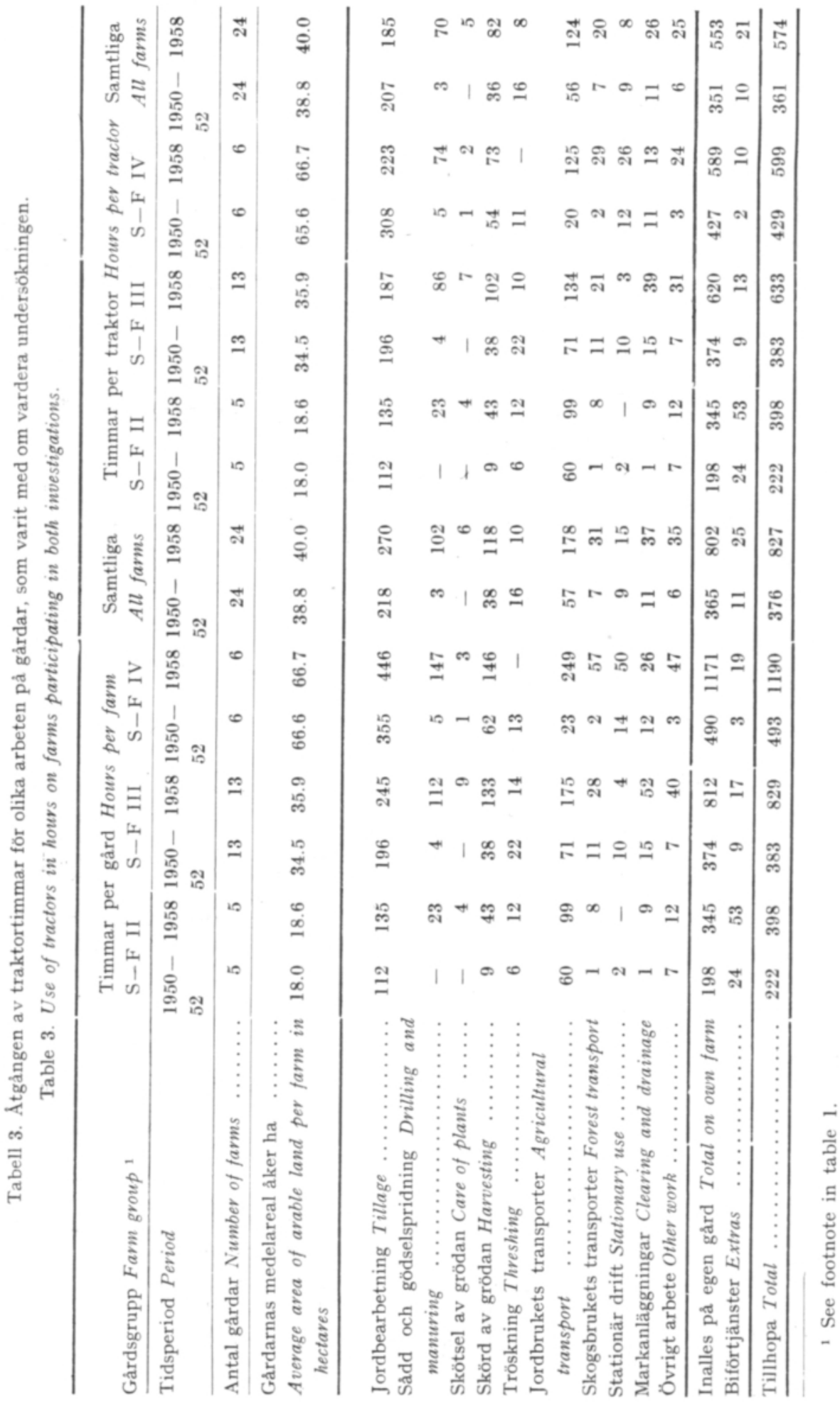


Tabell 4. Traktorredskapsuppsättningen i medeltal per gård.

Table 4. Average number of tractorequipments per farm.

\begin{tabular}{|c|c|c|c|c|c|c|c|c|}
\hline \multirow{3}{*}{$\begin{array}{l}\text { Traktorredskap } \\
\text { Tractor equipment }\end{array}$} & \multicolumn{4}{|c|}{ Gârdsgrupp } & \multirow{2}{*}{\multicolumn{2}{|c|}{$\begin{array}{l}\text { Farm group }{ }^{1} \\
\text { S - F IV }\end{array}$}} & \multirow{2}{*}{\multicolumn{2}{|c|}{$\begin{array}{l}\text { Samtliga } \\
\text { All farms }\end{array}$}} \\
\hline & \multicolumn{2}{|c|}{ S-F II } & \multicolumn{2}{|c|}{$\mathrm{S}-\mathrm{F}$ III } & & & & \\
\hline & $1950-52$ & 1958 & $1950-52$ & 1958 & $1950-52$ & 1958 & $1950-52$ & 1958 \\
\hline $\begin{array}{l}\text { Antal gârdar } \ldots \ldots \ldots \ldots \ldots \\
\quad \text { Number of farms }\end{array}$ & 5 & 5 & 13 & 13 & 6 & 6 & 24 & 24 \\
\hline $\begin{array}{l}\text { Dikesplog } \ldots \ldots \ldots \ldots \ldots \ldots \\
\quad \text { Ditch plough }\end{array}$ & - & 0.2 & & 0,2 & & 0.3 & - & 0.2 \\
\hline Plog Plough $\ldots \ldots \ldots \ldots \ldots$ & 1.0 & 1.2 & 1.0 & 1.5 & 1.3 & 1.2 & 1.1 & 1.4 \\
\hline Harv Harrow $\ldots \ldots \ldots \ldots$ & 1.0 & 1.4 & 1.2 & 1.5 & 1.3 & 1.5 & 1.2 & 1.5 \\
\hline $\begin{array}{l}\text { Gödselspridare } \ldots \ldots \ldots \ldots \ldots \\
\text { Manure spreader }\end{array}$ & - & & & 0.1 & & & - & 0.1 \\
\hline $\begin{array}{l}\text { Handelsgödselspridare } \ldots \ldots \ldots \\
\text { Fertilizer spreader }\end{array}$ & - & 0.4 & & 0.4 & 0.2 & 0.2 & 0.1 & 0.4 \\
\hline $\begin{array}{l}\text { Såningsmaskin } \ldots \ldots \cdots \cdots \\
\quad \text { Grain drill }\end{array}$ & - & & & 0.4 & 0.3 & 0.3 & 0.1 & 0.3 \\
\hline Vält Roller $\quad \ldots \ldots \ldots \ldots \ldots$ & - & & & 0.2 & & 0.2 & - & 0.2 \\
\hline $\begin{array}{l}\text { Ogrässpruta } \ldots \cdots \cdots \cdots \cdots \\
\quad \text { Weed sprayer }\end{array}$ & & 0.2 & & 0.2 & & & - & 0.2 \\
\hline Slâttermaskin Mower ..... & & 1.0 & 0.2 & 0.8 & 0.3 & 0.5 & 0.2 & 0.8 \\
\hline Självbindare Binder $\quad \ldots \ldots$ & & & 0.2 & 0.2 & 0.3 & 0.5 & 0.2 & 0.2 \\
\hline Släpvagn Trailer ......... & 0.4 & 1.0 & 0.2 & 1.2 & 0.5 & 1.2 & 0.3 & 1.2 \\
\hline Sladd Leveller $\ldots \ldots \ldots \ldots$ & & & & & 0.2 & & 0.1 & - \\
\hline Frontlastare Front loader .. & & & & 0.2 & & & - & 0.1 \\
\hline $\begin{array}{l}\text { Spillningsgrep } \ldots \ldots \ldots \ldots \\
\quad \text { Tractor manure fork }\end{array}$ & & 0.2 & & & & & - & - \\
\hline Hösläpa Hay sweep....... & & 0.2 & & 0.2 & & , & - & 0.2 \\
\hline Räfsa Hay rake $\ldots \ldots \ldots \ldots$ & & 0.2 & & 0.1 & & 0.3 & - & 0.2 \\
\hline $\begin{array}{l}\text { Schaktblad } \ldots \ldots \ldots \ldots \ldots \\
\quad \text { Earth moving plate }\end{array}$ & & 0.2 & & 0.2 & & 0.2 & - & 0.2 \\
\hline $\begin{array}{l}\text { Potatisupptagare } . . . \cdots \cdots \\
\quad \text { Potatoe spinner }\end{array}$ & & & & 0.2 & & & - & 0.1 \\
\hline Kultivator Cultivator ...... & 0.2 & 0.4 & 0.3 & 0.5 & 0.2 & 0.3 & 0.3 & 0.4 \\
\hline Snöplog Snow plough ...... & & & 0.1 & 0.1 & & & 0.1 & 0.1 \\
\hline Mullskopa Earth scoop $\ldots$. & & & & 0.2 & & 0.2 & - & 0.2 \\
\hline $\begin{array}{l}\text { Gallringsmaskin } \\
\text { Beet thinner }\end{array}$ & & & & 0.1 & & 0.2 & - & 0.1 \\
\hline $\begin{array}{l}\text { Potatisårder } \ldots \ldots \cdots \cdots \cdots \\
\quad \text { Potatoe ridger }\end{array}$ & & & & 0.1 & & & - & 0.1 \\
\hline $\begin{array}{l}\text { Rotfruktsupptagare } \ldots \ldots \ldots \\
\quad \text { Beet lifter }\end{array}$ & & & 0.1 & 0.2 & & & 0.1 & 0.1 \\
\hline $\begin{array}{l}\text { Röjningskrok } \cdots \cdots \cdots \cdots \\
\text { Clearing hook }\end{array}$ & & & & 0.1 & 0.2 & & 0.1 & 0.1 \\
\hline Vägskrapa Road leveller .... & & & & & & 0.2 & - & 0.1 \\
\hline $\begin{array}{l}\text { Summa traktorredskap } \\
\text { per gârd } \quad \ldots \ldots \ldots \ldots \ldots \ldots \ldots \\
\text { Total tractor equipment } \\
\text { per farm }\end{array}$ & 2.6 & 6.6 & 3.3 & 8.9 & 4.8 & 7.3 & 3.9 & 8.5 \\
\hline
\end{tabular}

1 See footnote in table 1. 
I tabell 2 återges samma resultat som i tabell 1 men framräknade per traktor.

En jämförelse mellan summasiffrorna i de bägge tabellerna utvisar, att timantalet per traktor icke stigit $i$ samma takt som timantalet per gård beroende på, att proportionsvis flera gårdar under den senare undersökningsperioden hallit sig med flera än en traktor, vilka inte utnyttjats lika effektivt, som var fallet då endast en traktor förekommit.

I syfte att erhålla en mera preciserad bild av utvecklingsförloppet återges i tabell 3 resultaten särskilt för de gårdar, som deltagit i bägge undersökningarna. Om man till en början granskar totala timantalet per gård för olika gårdsgrupper, framgår, att ökningen varit mest markant $\mathrm{i}$ den största storleksgruppen och svagast i den minsta.

En jämförelse mellan resultaten i tabell 3 och tidigare tabeller utvisar tydligt att traktorernas användning ökat mycket mera på de gårdar, som deltagit i bägge undersökningarna, än på samtliga gårdar. Under den första undersökningsperioden låg de förra tydligt under medeltalet för samtliga, under den senare över. Ökningen framträder inom samtliga storleksgrupper, tröskningen undantagen. Särskilt framträdande har traktoriseringen av sådd och gödselspridning, jordbrukets transporter samt skörd av grödan varit.

De i föregående tabeller framlagda resultaten utvisar, att samtidigt som antalet traktortimmar per gård och traktor starkt ökat har användningenäven blivit mångsidigare. I syfte att ytterligare belysa sistnämnda utveckling återges i tabell 4 jämförande siffror för uppsättningen av traktorredskap på de gårdar, som deltagit i bägge undersökningarna. Tabellens siffror kompletterar tidigare återgivna resultat och åskådliggör tydligt huru traktorredskapen ökat $\mathrm{i}$ antal och art.

\section{Slutsatser}

Undersökningens resultat ger anledning till följande slutsatser:

Medan traktorerna på de bokföringsgårdar, från vilka siffermaterial förelegat under tidsperioden 1950 - 52 i genomsnitt användes 453 tim. per gård resp 443 tim per traktor, utgjorde motsvarande tal år 1958625 resp. 560. En betydande ökning av traktorernas användningstid kan sålunda fastslås ha ägt rum.

Traktorerna utnyttjades under den senare perioden på ett betydligt mångsidigare sätt än under den förra perioden. Den mångsidiga användningen kommer till uttryck främst genom en ökad insats av traktorerna i sådd och gödselspridning, skötsel av grödan, skörd av grödan och transporter.

Samtidigt, som det är uppenbart, att traktorernas insats är större och mångsidigare på större gårdar än på mindre, tyder resultaten på, att en fortgående traktorisering medför, att skillnaden mellan mindre och större bokföringsgårdar synes öka, då man uttrycker traktoriseringens omfattning genom timåtgången per gård.

De gårdar, som deltagit i bägge undersökningarna, representerar gårdar som år 1958 nått fram till en mera avancerad traktorisering än vad fallet är med samtliga i undersökningen år 1958 deltagande gårdar. Det faktum, att traktoranvänd- 
ningen på dessa gårdar ökat mycket mera än vad en jämförelse mellan traktoranvändningen på samtliga gårdar åren 1950 - 52 respektive 1958 ger vid handen, talar för att goda möjligheter, att effektivare utnyttja traktorer föreligger överhuvudtaget på gårdar, som befinner sig i ett begynnande traktoriseringsskede.

En skenbart motsägande bild lämnar emellertid timåtgångens utveckling i storleksgruppen S-F IV. Det förefaller som om man vid en utökning av antalet traktorer per gård inte mera lika effektivt utnyttjar traktorerna som fallet var då gårdarna höll sig med färre traktorer.

Denna undersökning har utförts med stöd av forskningsanslag från Henry Fords stiftelse. Det är författarnas angenäma plikt att till stiftelsen framföra sitt uppriktiga tack härför.

S U M M A R Y :

PROGRESS IN THE USE OF TRACTORS ON A NUMBER OF FINNISH BOOKKEEPING FARMS

N. Westermarck and K. J. WECKMAN

Department of Agricultural Economics, University of Helsinki

Object and Scope of the Investigation. During the years 1950, 1951 and 1952 an investigation was carried out at the Department of Agricultural Economics at the University of Helsinki, relating, among other things, to the use of tractors on 65 bookkeeping farms. The object of the present investigation is to ascertain to what extent changes have taken place since those years in the use of tractors and in the distribution of the time consumption among the various labour operations to which the tractors have been put. The investigation covered 240 farms and one year, i.e. the calendar year 1958.

Results of the Investigation. The small number of farms (only 24) which participated both in the $1950-1952$ investigation as well as in the present one, naturally constitutes a weak point when comparing the results of the two studies with each other. But on the other hand, the marked increase in the number of tractorized bookkeeping farms reflects the development which has actually taken place during the 1950's. The results of the investigation are revealed in Tables $1-4$.

\section{Conclusions}

The results of the study lead to the following conclusions:

Whereas tractors on all the bookkeeping farms for which figures are available for the $1950-1952$ period were employed for 453 hours per farm and 443 hours per tractor on the average, the respective figures in 1958 were 625 and 560 . A significant increase in the use of tractors is accordingly confirmed.

During the later time-period, tractors were employed for an appreciably greater variety of purposes than during the first-mentioned period. The manifold use of tractors is seen, above all, in their increased employment in drilling and manuring, in harvesting of crops and in transportation.

While it is obvious that tractors are put to greater use on large farms than on small farms, the results seem to indicate that progressive tractorization leads to an increase in the difference between small and large farms, if the extent of tractorization is expressed as the time consumption per farm. 
The stage of tractorization represented in 1958 by the farms which had participated in both investigations was more advanced than that represented by the total number of farms participating in the 1958 investigation. The fact that the use of tractors on these farms increased much more than a comparison between the use of tractors on all farms during the years 1950 and 1958 would suggest, shows that there are, in general, favourable possibilities of a more effective utilization of tractors on farms in the initial stages of tractorization.

An apparently contradictory picture is given by relating to the time consumed in the S-F IV size category ( $>50$ hectares). It appears that when the number of tractors on a farm is increased, they are utilized less efficiently than when the farm kept fewer tractors.

This study was conducted with the support of the Henry Ford Foundation. It is the pleasant duty of the writers to convey their sincere gratitude to the Foundation for its support. 